\title{
On Cultural Default and Compensation in Big Breasts and Wide Hips From the Perspective of Cultural Schema Theory
}

\begin{abstract}
YU Jie-li
Ningbo Dahongying University, Ningbo, China

Cultural schema theory proposes that when we interact with members of the same culture in certain situations, or talk about certain information with them many times, cultural schemas are created and stored in our brain, which can promote coherence between the original and target language text, thus solving the cultural default caused by the cultural differences. It is vital to make cultural compensation to different cultural schemas and to coordinate the cultural contradiction. This thesis focuses on the translation methods and strategies in Big Breasts and Wide Hips from the perspective of the cultural schema theory, which exemplifies how cultural default and compensation functions in this novel.
\end{abstract}

Keywords: cultural schema theory, cultural default, compensation, Big Breasts and Wide Hips

\section{Introduction}

As one of the representative works of MO Yan, Big Breasts and Wide Hips vividly reproduces the turbulent Chinese society in the 20th century and shows the difficult life of an ordinary mother. The English translation was completed by the Howard Goldblatt, who is characterized as witty language skill and rich cultural connotation. His translation version is unique in style and creative in content, always putting top priority to the target readers' feeling and experience. Howard Goldblatt retained a cultural aesthetic value of the original text and achieved the mental communication with the target readers. His work, full of humorous and witty remarks, is a combination of oriental flavor and Western logical thinking. That is the reason why both Eastern and Western readers take an intense interest in it.

In this paper, the English version of Big Breasts and Wide Hips translated by Howard Goldblatt is used as a model to explore the cultural translation default and cultural compensation strategies. According to Wikipedia, cultural schema theory proposes that when we interact with members of the same culture in certain situations many times, or talk about certain information with them many times, cultural schemas are created and stored in our brain. The paper will conduct research on how the default and compensation is achieved in the translation version in order to promote cultural transmission. The paper starts with an introduction to the theory and its main application in translation. The main part of the paper focuses on the cultural default translation compensation research in this novel. The compensation strategies of cultural deficiency in the English version will be summarized in the paper as well.

YU Jie-li, undergraduate, School of Humanity, Ningbo Dahongying University. The paper is under the supervision of Ms. WANG Qi. 


\section{Cultural Schema Theory Research}

\section{Cultural Schema Theory Connotations}

A cultural schema is relatively frequently used in the process of human memory storage, which is derived from the society and cultural background knowledge including personal life and social practical experience. The notion of cultural schema plays a pivotal role in cognitive understanding. The special schema state stored in brain for searching and updating at the cultural schema which is a kind of memorizing structure is derived from the meaning of joining the new information gathered from an extensive literature or reality obtained by individual with their own personal life or social practical experience. "The organization of knowledge in human cognitive process involves units that are larger than words and concepts. This organization also includes knowledge about familiar situations, events, and the relationship among these situations and events" (Matlin, 2008 , p. 228). People may naturally adapt the previous knowledge through exposure to a fresh cultural environment, which differs schema could vary the interpretation towards the original text. When reading numerous materials available, people intensively facilitate to search or update schema that they already gathered to achieve a completed schema built by numerous blocks of memory schema. Schemas will record automatically about what has been learned, where the community is or which cultural knowledge background surrounded by-all information will be collected and analyzed as a total summary. For the reading comprehension purposes, people use a series of figures and existing knowledge schemas to extend cognitive models once they stimulate relevant information. For instance, the classroom schema describes a series of senses may appear in the classroom. In this illustration, "teacher", "student", “desk", "blackboard", "chalk", "computer", and "projector" formulate specific signals to activate classroom scenarios in a text or real conversion. All of the displayed information is activated to render the image in the brain. The interactive signals of teacher schema, like "student" and "teacher" can be activated and thus trigger next comprehensive schema and activate the schema as a whole. In this context, the cultural schema is a sequence of knowledge structure.

Cultural schema is generally related with historical and social context, so cultural schema will constantly update with characteristics of their specific cultural in a long-term knowledge accumulation. A unique cultural cognitive system and values will be formulated influenced by the way of social communication, the process of historical development and faith of human beliefs. For example, westerners consider being tanned as a healthy and positive performance, however, in Chinese concept, white skin can cover all flaws. Clearly, people from diverse cultural background always have a variety of cultural cognitive notion. Therefore, cultural schema is a kind of shared knowledge structure.

Last but not least, basically in the related cultural background, people usually can successfully participate in a dialogue. It is thoughtful to investigate on the phenomenon that two individuals from different countries have a smooth conversion. This situation indicates that one of listener and speaker's cultural schema may have changed. The emergence of this model shows that fresh information will apparently comprehend in the existed cultural schema; brain will give enough enforcement on the appearance of new things with analyzation and sort through the relevant schemas. Cultural schema will continue to broaden its application and cooperation with the progress of times. Therefore, the cultural schema is a plasticity of the knowledge structure.

\section{The Application of Cultural Schema Theories in Translation}

The process of translation is not only to find appropriate and interpretation in the source language and 
target language, which is to deal with cultural default and conflict in the texts. First of all, translator needs a preliminary understanding of the contextual relationship between the author's cultural background and target language and discerns the existence of cultural defaults. If a translator relies on a considerable explanation of his or her own cultural background knowledge in the process of translation, readers who have less or no schema related to the reading materials will be disadvantaged in this situation, which will give total disruption on what they read or demotivate them to read. Because of cultural background differences, cultural defaults in the translation inevitably may lead to misunderstandings of readers. Readers will activate their schemata concerned to fill in the slots of the schemata left by cultural default in occurrence on some keys shown in the text. Apparently, cultural schema plays a pivotal role in cultural translation.

In recent years, cultural schema theory aroused many scholars concerns in the field of translation applications. SHANG Jing puts forward that cultural schema should focus on reader's previous cultural background knowledge to evoke familiar situation in cultural translation. Readers will mirror similar schemas to compare the difference between them. In this article, the author suggests that foreignizing translation strategies should be used in the process of cultural default translation.

HUANG Fen chooses Fortress Besieged as its research model to analyze cultural connotation in the system and found that translators use the theory as their cultural guidance to compensate the cultural defaults. The author also discusses problems existing in semantic expression of translation and enriching coherent interpretation of the text through the cultural schema theory. Readers will experience the pleasure of reading the literature under the cultural schema theory.

LIANG Yu-qiong focuses on the study of literary works by cultural default with the help of Chinese proverb and explores the cultural default and compensation. Chinese proverb with great Chinese characteristics conveys various Chinese cultural, belief, history, etc. that may cause the difficulties in semantic interpretation and cultural defaults and compensation. The author tries to find appropriate compensation strategies to improve an accurate and interpretation from the cultural schema theory.

According to Susan Bassnett, she believes that translation is an act deeply rooted in the cultures of languages and it is both the intra-cultural communication and the inter-communication. (Susan Bassnett, 2013) In Discourse Analysis (2012), Brown and Yule examine the view that "schemas can be seen as the organized background knowledge which leads us or predict aspects in our interpretation of discourse" (2012, p. 248). Kronenfeld states the positive effect of schemas in Culture, Society, and Cognition (2008), presenting that schemas are reconstructed and alterable in the process of studying or living.

From domestic research discussed in this fields, the cultural schema theory literature is generally used in the translation of Chinese cultural elements in the novel, proverb translation, culture-loaded word translation studies, and literary translation. Among them, the study of cultural schema theory for translators is mainly focused on the theoretical level. The compensation and default analysis from cultural schema theory is not much probed by scholars. In the theoretical application, cultural schema theory is often used to construct new schemas, but there is a lack of methodological theory to analyze case studies.

Cultural schema theory constructs a new cultural schema from the perception of the default between the original and translation. It is the tool of finding the differences from different cultural background knowledge system. In the course of translation, the translator activates the existing cultural schemas in the brain to find similar cultural graphs and searches for the meaning blanks about the cultural background, trying to combine the common sense and the experience to establish the coherence of language and culture between the text and 
potential target language readers. So this requires further study of cultural default and compensation with cultural schema theory.

\section{Cultural Default in Big Breast and Wide Hips}

Translation is a process in which two cultures collide and coordinate with each other. The biggest challenge for translators is solving cultural default and overcoming barriers between source language and target language. According to Research into Cultural Default in Translation (WANG, 2012), cultural default refers to the gap between the author and the potential purpose and the exchange of information between readers and similar cultural background pattern blank. When interlocutors who share same cultural background knowledge are engaged in verbal communication or text reading, their conversation is still successfully established. Those who are reading a text with unfamiliar cultural schema have more difficulties in achieving the exact meaning of text or even have none available comprehension regarding their previous cultural background schema. Normally, the author will omit the concept which already exists in his or her culture; however, for the members within a different language cultural, they may have some cultural defaults about the text. The cultural schema theory gives the maximum support of realizing cultural communication and facilitating semantic structure.

Thus, there is a variety of cultural contextual patterns in communication between the author and potential target readers, which leads to cultural defaults in the reader's reading.

Big Breasts and Wide Hips was written by MO Yan in honor of his mother whose image is far from the traditional concept. The novel gives broad brush strokes of the mother in a delicate way. It is full of rich cultural elements revealing unique cultural customs of Northern China. Chinese readers are long exposed to the Chinese cultural society, so it is easy for them to connote Chinese dialects, idioms, and characters. In contrast, Western readers share different cultural schemas, so they make no attempt to join the text reading. The cultural default shared by writer and intended readers brings about the issues that readers fail to obtain the accurate text meaning.

\section{Cultural Default Caused by Idioms in Big Breasts and Wide Hips}

Idioms, slang, or proverbs are the witnesses of history and are also the inheritors of language and culture. Idioms are a fixed usage in daily life which is often expressed profound truth with concise and clear language. In the translation of language and culture, it is necessary in order to retain the artistic motive and aesthetic value in the original works and to respect the reading habit of the potential target language readers, so the translator needs to carefully examine the verbal expression.

Such as Big Breasts and Wide Hips:

Example (1) Original: 婆婆把几颗花生塞到她的手里, 教她说: “花生花生花花生, 有男有女阴阳平”。她接过花 生, 感激地重复着婆婆的话: “花生花生花花生, 有男有女阴阳平”。(MO, 2012, p. 8)

Translation: "Her mother-in-law thrust some peanuts into her hand and told her to say, 'Peanuts peanuts peanuts, boys and girls, the balance of yin and yang'. Gratefully wrapping her hand around the peanuts, she repeated the mantra: 'Peanuts peanuts peanuts, boys and girls, the balance of yin and yang'”. (Goldblatt, 2012, p. 7)

The idiom, "Peanuts peanuts peanuts, boys and girls, the balance of yin and yang" from the original text, is familiar with the Chinese expression. In China's hi culture, giving birth with peanuts is a good word or auspicious time, which indicates that fertility will be a good thing that to come and the baby is a healthy boy. In her birth, Shangluo Lu's mother-in-law puts peanuts into her hands, which indicates that the elder woman is 
eager to have a baby who can afford the whole family. Shangguan family has eight daughters in the name of all containing "male" word which shows the extreme desire of male ethnic groups, while the performance of the old society of male sovereignty of the customs has been revealed. The concluding part of the sentence is "boys and girls, the balance of yin and yang" which contains the concept of yin and yang theory. The concept of "yin and yang" comes from the understanding of the ancient world of nature, all the opposites but linked to the objective existence of things rise to its high level of spiritual and philosophical generalizations. Shangguan family already has eight daughters, Shangguan Lu's mother-in-law hopes that this one is able to regulate the balance of yin and yang at home and inherit the blood. This example relates to Chinese traditional idioms, "peanuts" and "yin and yang". When Chinese readers read this example, they will automatically associate social and cultural contextual illustrations related to their own national conditions. However, Western readers do not have this history of cultural background picture; the potential connotation of the original text cannot be grasped. Western readers cannot accurately understand the meaning of context, while cultural schema blank is likely to cause misunderstanding of the original text. Mr. Howard uses the literal translation method to make up the cultural schema blank between the reading text and Western readers so that they can comprehend interpretation easily and experience the aesthetic value in original text. In this case, therefore, the literal translation method is able to make up for the cultural default of the reading barrier in order to retain the original text of the elegant and the author created the reader to play the imagination of space.

Example (2) Originial: 上官吕氏叹息一声, 道: “是福不是祸, 是祸躲不过。还愣着干什么? 快给它按肚皮! ” (Mo, 2012, p. 10)

Translation: Shangguan Lü sighed. "If the signs are good, we'll be all right. If not, there's nothing we can do about it. So get to work and push down on her belly". (Goldblatt, 2012, p. 11)

In this case, from the literal understanding of "shifubushihuo, shihuoduobuguo". This sentence stems from Laozi Chapter 58, which means that the development of things is a blessing or a disaster is destined for legend. In the original text, Sima Ting spread the message that the Japanese army is about to sweep the village urged the villagers to escape as soon as possible to avoid the danger. Shangguan Shouxi was horrified to hear the news, urging his mother to drop the donkey being produced and everyone goes out to avoid disaster. However, the Shangguan Lü did not want to leave. This sentence implied that she believes that the whole family can escape this catastrophe depending on God's decision, life determined by the strong feeling of heaven regardless of retention or escape from the village fate already decided. In the translation, Howard Goldblatt used the method of literal translation which is based on the author's original intention and contextual association to add "sign" and "we" in the English version, creating a new cultural schema to compensates Western readers' cultural schema default.

\section{Cultural Default Caused by Special Words in Big Breasts and Wide Hips}

In the process of the development of history and culture, many words with cultural characteristics have been created. Because of their abundant cultural connotation, there may be cultural default in the process of translation missed. Such as in Big Breasts and Wide Hips:

Example (3) The original text: 往常里穿绸披锻、涂脂抹粉的福生堂女眷, 为何打扮成这副模样? (MO, 2012, p. 1)

Translation: Why are these women, who normally dress in silks and satins, and are never seen without rouge and lipstick, dressed like that? (Goldblatt, 2012, p. 1) 
The original text of "chuanchou piduan" and "tuzhi mofen" is not familiar to the target language readers, which uses vocabulary with Chinese characteristics to the woman like wearing silk products, only the royal pro-nobility has a bright color and texture smooth clothing, which can be seen as an elegant representative. "tuzhi mofen" in turn from Erke Paian Jingqi in the Ming Dynasty means his wife dressed her beauty with jewelry. As related cultural background, Chinese readers can immediately grab the original text. While Western readers lack the corresponding cultural background for the image of the classical Chinese women who may fail to guarantee the meaning. Mr. Howard carries out the cultural reappearance depending upon the presupposition of the cultural background knowledge schema of the target language reader and its background. The Western readers can easily realize the author's writing depending on the existing cultural schema and the Western readers can use the explicit schema of the Western literary culture to show the characteristics of the original words, such as "rouge" and "lipstick". Western readers can easily comprehend the author's writing intention according to the existing cultural schema, so that Western readers can appreciate the originality of the original aesthetic characteristics.

\section{Cultural Default Caused by Dialect in Big Breasts and Wide Hips}

Dialect is the Chinese language and culture in the thriving, which not only contains beyond the structure of the Mandarin system and has the various regional history cultural backgrounds. Dialects contain vivid information and complex system of a certain cultural schema which is closely related to people's life and reflects specific regional cultures. As in Big Breasts and Wide Hips:

Example (4) Original: 上官吕氏大声道: “嗨, 清晨放枪, 大司马又犯了魔怔!” (MO, 2012, p. 5)

Translation: "The devil's gotten back into that old bastard Sima, firing his gun so early in the morning!" Shangguan Lü announced. (Goldblatt, 2012, p. 4)

This sentence illustrates that Shnaguguan Lü hated the behavior of Sima Ting shooting the gun in the morning. In Chinese version, "fanle mozheng" means someone behaves abnormal as a result of being psychologically damaged, this word contains strongly annoying and hateful emission. Most of the people living in the area understand the meaning and emotional nature of the word. Shangguan Lü's words in the language of the expression, obviously exposing her dare to the true nature of love. In the translated version, Mr. Howard translates "mozheng" into "the devil's", which accurately grasps the inner feelings of the dialect. He also adjusted the order of words to deal with better and inherited the text of the visual form of language. When Western readers read this sentence, according to its original cultural schema will be linked to devil and evil things to know the true meaning of the dialect.

Example (5) Original: “福生堂大掌柜的又放枪又吆喝......” 上官寿喜抬起一条胳膊, 用沾满驴毛的手背指着脸 上的汗水, 低声嘟哝着”。(MO, 2012, p. 9)

Translation: "The steward at Felicity Manor has been firing his gun and sounding the alarm", Sahnggguan Shouxi muttered as he wiped his sweaty face with an arm covered with donkey hairs. (Goldblatt, 2012, p. 8)

The word "yaohe" in the text is derived from the cries of the old Beijing traders selling and selling in the market, followed by similar claims spread to various regions of China. People normally known as "yaohe" that the behavior of loud selling showing China has bustling marketplace customs and folk culture. In this case, the shopkeeper fired shots rather than actually shouting to warn the villagers of danger. Western culture, the reader 
cannot understand the meaning of the word because there is no similar cultural background schema. Mr. Howard contributes to solve the cultural default, which selects the familiar cultural schemata of the Western readers instead of translating directly the literal meaning of "shouting" and expressing derived words.

\section{Cultural Compensation in Big Breasts and Wide Hips}

Because the cultural default and implicit culture's artistic connotation cannot balance each other's language structure, the translator needs to choose the appropriate language expression and explanation in the source language and the target language, which requires the translator to adopt the cultural compensation method to the default part to supplement and to enrich the language level of the article.

This not only requires readers to grasp the source language of the literal meaning and grammatical structure but also has the ability to control the cultural default in the compensation translation, which is more proficient in words and phrases implied cultural background schema. Because of the differences between the cultural backgrounds, the translation can be achieved with the original art similar to the effect. In literary works, the cultural backgrounds displayed in the original text are different from the cultural symbols of the target language readers, and some semantic misinterpretations occur in the spiritual communication between the two sides. The cultural schema can promote cultural exchange and promote the development of literature. Cultural compensation for the default part of the cultural schema will automatically successfully activate.

As for the cultural default compensation in the Big Breasts and Wide Hips, Mr. Howard used the idea of breaking the traditional, unique and novel translation idea to recreate the translations on the basis of faithfulness to the original translation. A comparative analysis of the original and the translations of this book reveals that Mr. Howard is using a different kind of compensation for the cultural schema defaults.

\section{Supplementary Compensation in Big Breasts and Wide Hips}

In the article translation, the supplemental compensation maintains the foundation of the cultural and artistic beauty of the original text and increases the construction of the cultural background knowledge schema for the target language reader. The reader can quickly resonate with the text and enter the story described in the plot. For example, in the Big Breasts and Wide Hips:

Example (6) Original: 马洛亚牧师提着一只黑色的瓦罐上了教堂后边的大街, 一眼便看到, 铁匠上官福禄的妻 子上官吕氏弯着腰, 手执一把扫炕答帚, 正在大街上扫土。(MO, 2012, p. 1)

Translation: From where he lay quietly on the brick-and-tamped-earth sleeping platform, his kang, Pastor Malory saw a bright red beam of light shining down on the Virgin Mary's pink breast and on the pudgy face of the bare-bottomed Blessed Infant in her arms. (Goldblatt, 2012, p. 1)

In this case, Mr. Howard reproduces the implied meaning of kang in the English translation. In the Northern Chinese living custom, kang more refers to the bed with brick or brick into the construction of the bottom of the pipeline or flue with a heating bed. Mr. Howard considered that the Western readers may not have the historical cultural background behind the kang, and adopts the supplementary strategy to compensate for the cultural default in the translated version. He adds "sleeping platform" indicates that the Kang is furniture used for sleeping. A clear interpretation of the translation arrangements will help Western readers understand the meaning of cultural term. On the basis of the original cultural schema, Western readers construct a new cultural schema, which announces that the reader can meet the cultural meaning of the author's creation in the translation. 


\section{The Interpretation of Compensations in Big Breasts and Wide Hips}

When certain words in the original text conflict with the target language by the expression or cultural background, the translator usually uses the method of interpretation to translate and interpret a concrete object directly. This method is relatively free and easy expression in the translation language and can retain the core of the original.

Example (7) Original: 上官吕氏把籍箕里的尘土倒在揭了席、卷了草的炕上，忧心忡忡地扫了一眼扶着炕沿低 声呻吟的儿媳上官鲁氏。(MO, 2012, p. 5)

Translation: Shangguan Lü emptied her dustpan onto the exposed surface of the Kang, whose grass mat and bedding had been rolled up and put to one side, then cast a worried look at her daughter-in-law, Shangguan lu, who moaned as she gripped the edge of the kang. (Goldblatt, 2012, p. 4)

In this case, the original meaning of the mat means that the mat is woven in sheet form with reeds or grass, which is usually laid on the kang or on the bed in order to rest. In English-speaking countries, people rarely have mats at home. It is easy to misunderstand the original text for the potential Western readers do not have the cultural background of the schema. Mr. Howard uses the interpretation of the means, in the translation of the mat in the production of raw materials directly and the plentiful use of the translation of the plot here.

Example (8) Original: (孙大姑冷笑一声, 走上前去, 把马洛亚搡到一边去)牧师身体趔䞟着, 睁开眼睛, 口吐一 个“阿门”, 手指在胸前上划个“十”字, 结束了他的长篇祝祷。(MO, 2012, p. 46)

Translation: His "Amen" came as he stumbled wide-eyed to keep his balance, hurriedly crossing himself to bring his prayer to an end. (Goldblatt, 2012, p. 44)

In the Chinese expression, the author likes to use the cultural characteristics of the verb to describe the details of the characters to promote the development of the special context of the plot. However, Western people tend to have clear structure and logical thinking in literary expression. In this example, "lieqie" is a verb describing the instability because of some factors. Taking into account the cultural background of Chinese characteristics, Mr. Howard combined this action with a series of descriptions that are familiar to the Western Christians like "cross" "prayer". In this way, the culture schema is based on the cultural interpretation and description.

\section{Replacement Compensation in Big Breasts and Wide Hips}

If similar equivalence can be found in the target language, target readers will formulate their cultural schemas on their own. For the target language reader, the familiar language statement makes the article smooth and easy to understand, eliminating the barriers which are brought by cultural default.

Example (9) Original: “菩萨保佑.....祖宗保佑......所有的神、所有的鬼, 你们都保佑我、饶恕我吧,让我生个全 毛全翅的男孩吧......我的亲亲的儿子，你出来吧......公地母、黄仙狐精，帮帮我吧.....” (MO, 2012, p. 5)

Translation: "Lord in Heaven, protect me... Worthy Ancestors, protect me... god and demons everywhere, protect me, spare me, let me deliver a healthy baby boy... my very own son, come to Mother... Father of Heaven, Mother of Earth, yellow spirits and fox fairies, help me, please..." (Goldblatt, 2012, p. 5)

The original meaning of "Bodhisattva Blessedness" is originated from Bodhisattva in Chinese Buddhism. It means that a man having suffered tremendous mistresses will turn self-sacrificed, devoting to all good deeds. Buddhism has a long history of communication and development in China, so people often pray for unexpected 
or beyond the scope of things, trying to seek spiritual comfort from Bodhisattva the protection of the Lord Buddha. There is a similar religious cultural schema in the western cultural schema, where Jesus is regarded as the ancestor who are praised and followed by sentient beings. Because the target language is closely related to cultural background Mr. Howard used replacement compensation so that Western readers can easily understand the meaning of which is interpreted.

\section{Conclusion}

The paper aims to provide a perfect intercultural communication between the original texts and the target language readers with the theoretical framework of cultural schema theory as a functional and practical guidance which solves cultural default caused by unclear interpretation the adoption of appropriate compensation methods in literature. Through the example of Big Breast and Wide Hips, the cultural schema theory is used as the basis to study and analyze the problems existing in the cultural translation and the appropriate compensatory means to keep the original aesthetic value as far as possible to create the favorite works of the readers, and ultimately achieve the purpose of dissemination of Chinese culture.

\section{References}

Bassnett, S. (2013). Translation studies. London: Routledge.

Brown, G., \& Yule, G. (2012). Discourse analysis. Beijing: Foreign Language Teaching and Research Press.

Goldblatt, H. (2012). Big breasts and wide hips. London: Methuen Publishing.

HUANG, F. (2012). 文化图式理论视角下《围城》中文化因素的英译研究 (On the English translation of cultural factors in fortress besieged from the perspective of cultural schema theory) (pp. 1-58). Hunan: Hunan University.

Kronenfeld, D. B. (2008). Culture, society, and cognition: Collective goals, values, action, and knowledge. Berlin: Walter de Gruyter.

LIANG，Y. Q. (2014). 从文化图式理论看汉语浐语翻译中的文化缺省及其补偿 (On cultural default and compensation in Chinese proverb translation based on cultural schema theory) (pp. 1-59). Guangxi: Guangxi University.

Matlin, M. W. (2008). Cognition. New York: Wiley.

MO, Y. (2012). 丰乳肥壂 (Big breasts and wide hips). Shanghai: Shanghai Literature and Art Publishing Group.

SAHNG, J. (2012). 从文化图示理论的视角探究文化缺省的翻译 (On the translation of cultural default from the perspective of cultural schema theory-With a case study of Goldblatt's translation of big breasts and wide hips) (pp. 1-60). Shanghai: East China Normal University. 